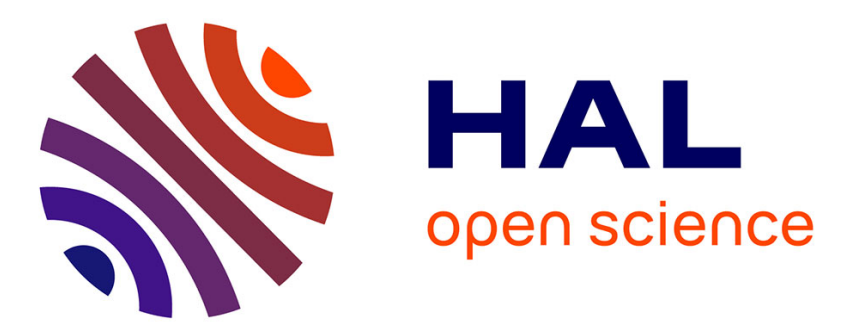

\title{
Bond Lengths and Elasticity in Strained-Layer Semiconductors
}

J. Woicik, J. Pellegrino, K. Miyano

\section{To cite this version:}

J. Woicik, J. Pellegrino, K. Miyano. Bond Lengths and Elasticity in Strained-Layer Semiconductors. Journal de Physique IV Proceedings, 1997, 7 (C2), pp.C2-687-C2-689. 10.1051/jp4:1997205 . jpa00255151

\section{HAL Id: jpa-00255151 https://hal.science/jpa-00255151}

Submitted on 1 Jan 1997

HAL is a multi-disciplinary open access archive for the deposit and dissemination of scientific research documents, whether they are published or not. The documents may come from teaching and research institutions in France or abroad, or from public or private research centers.
L'archive ouverte pluridisciplinaire HAL, est destinée au dépôt et à la diffusion de documents scientifiques de niveau recherche, publiés ou non, émanant des établissements d'enseignement et de recherche français ou étrangers, des laboratoires publics ou privés. 


\title{
Bond Lengths and Elasticity in Strained-Layer Semiconductors
}

\author{
J.C. Woicik, J.G. Pellegrino and K.E. Miyano* \\ National Institute of Standards and Technology, Gaithersburg, Maryland 20899, U.S.A. \\ * Department of Physics, Brooklyn College, Brooklyn, New York 11210, U.S.A.
}

\begin{abstract}
The $\mathrm{x}$-ray standing wave (XSW) and extended $\mathrm{x}$-ray absorption fine structure (EXAFS) techniques have determined the strain and bond distortions in an InAs monolayer embedded in GaAs(001). A unifying picture of bond lengths and elasticity in strained-layer semiconductors is presented.
\end{abstract}

When a thin semiconductor film with lattice constant a is grown coherently on a substrate with different lattice constant $a_{s}$, the layer experiences a tetragonal distortion. For an isotropic cubic layer grown on an (001) substrate, macroscopic-elastic theory ${ }^{1}$ relates the layer's strain parallel $\varepsilon_{/ /}=(\mathrm{a} / /-\mathrm{a}) / \mathrm{a}$ and perpendicular $\varepsilon_{\perp}=\left(\mathrm{a}_{\perp}-\mathrm{a}\right) / \mathrm{a}$ to the interface through the elastic constants $c_{11}$ and $c_{12}$ by

$$
\varepsilon_{\perp}=-2\left(c_{12} / c_{11}\right) \varepsilon_{/ /}
$$

Due to the technological importance of heterojunction devices it is not surprising that EXAFS has been used to study the local structure of these layers in detail; however, it is surprising that -- despite the consensus that bond lengths have a strong tendency to remain close to their natural values -- numerous conflicting reports on the microscopic strain state have been put forward. In some cases the strain has been found to have remarkable effects on bond lengths, 2,3 while others have found little or no effect. ${ }^{4-8}$ Others yet have reported the counterintuitive result that bonds actually elongate in layers under compression. ${ }^{9}$

In this work we apply two independent atomic-scale probes: XSW, which accurately measures the perpendicular distance of foreign atoms relative to the diffracting planes of a host crystal, and EXAFS, which precisely measures their near-neighbor bond lengths, to obtain the microscopic structure of the buried 1 monolayer (ML) InAs/GaAs(001) interface. This interface is ideal for addressing the issue of bond-length strain because it is one of the most highly strained semiconductor combinations available; it possesses a strain equal to $7 \%$, which corresponds to a critical thickness of only - 1.5 ML. 10 Not only does it challenge macroscopic theory itself, but it should also make the mictoscopic consequences of strain large enough to be measured.

To begin, let us consider the tetrahedron of figure 1 , which is under compressive strain in the $x y$ plane. We may estimate the effect of this strain on the bond lengths and angles of the tetrahedron as follows. The lattice parameters parallel and perpendicular to the $x y$ plane are given in terms of the first-neighbor distance $r$ and the bond angle $\theta$ by

$$
a_{\perp}=4 r \cos (\theta / 2) \text { and } a / /=2 \sqrt{2} r \sin (\theta / 2)
$$

Differentiating and retaining terms to first order yields

$$
\varepsilon_{\perp}=\Delta \mathrm{a} \perp / \mathrm{a}=(\Delta \mathrm{r} / \mathrm{r})-\sqrt{ } 2 / 2(\Delta \theta) \text { and } \varepsilon_{/ /}=\Delta \mathrm{a} / / \mathrm{a}=(\Delta \mathrm{r} / \mathrm{r})+\sqrt{ } 2 / 4(\Delta \theta)
$$

This equation relates the macroscopic strains to the microscopic distortions $\Delta r$, the bond stretch, and $\Delta \theta$, the bond bend. Rewriting equations 3 we arrive at

$$
\varepsilon_{\perp}=-2[(1-\sqrt{2} \alpha) /(1+2 \sqrt{2} \alpha)] \varepsilon_{/ /}
$$

where $\alpha \equiv(\Delta r / r) /(\Delta \theta)$ is defined as the ratio of the bond stretch to bond bend. Solving equations 1 and 4 enables us to write $\alpha$ solely in terms of the macroscopic elastic constants $c_{11}$ and $c_{12}$ :

$$
\alpha=\sqrt{2} / 2\left[\left(1-\mathrm{c}_{12} / \mathrm{c}_{11}\right) /\left(1+2 \mathrm{c}_{12} / \mathrm{c}_{11}\right)\right] \text {. }
$$




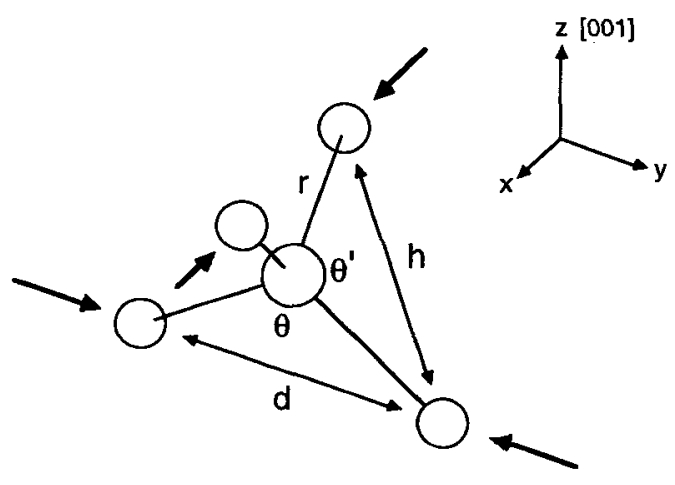

Figure 1: An InAs tetrahedron under compressive strain in the $x y$ plane. The in-plane and out-of-plane second-neighbor distances are $d=2 r \sin (\theta / 2)$ and $h=2 r \sin \left(\theta^{\prime} / 2\right)$.

Table 1: The calculated In position above the last As layer of the GaAs substrate from macroscopic-elastic theory and from bond-length and bond-angle conservation. Also shown is our standing-wave result and the position of the layer had it not been strained.

\begin{tabular}{lc}
\hline \hline Theory or experiment & In-As planar distance $(\AA)$ \\
\hline Bond-angle conservation & 1.41 \\
Unstrained & 1.51 \\
Macroscopic-elastic theory & 1.62 \\
Bond-length conservation & 1.72 \\
$\quad x S W$ & $1.64 \pm 0.03$ \\
\hline
\end{tabular}

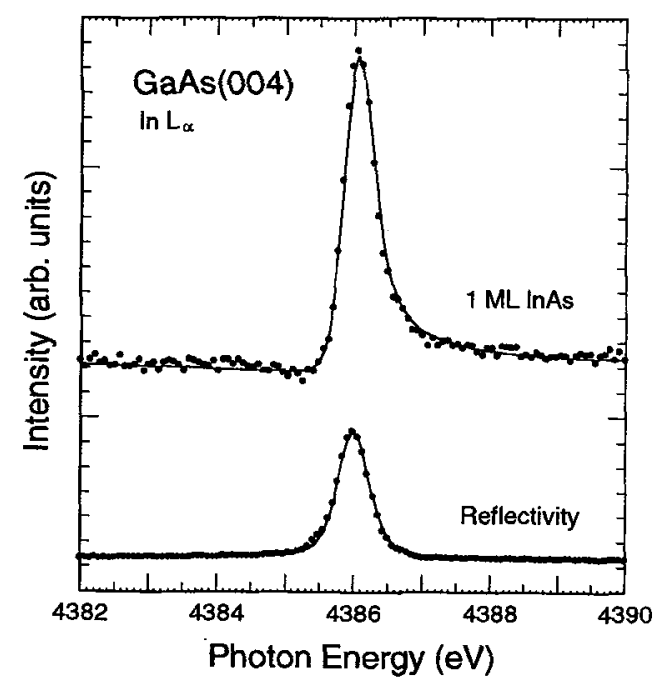

Figure 3: In-L ${ }_{3}$ EXAFS from the InAs monolayer (middle) and bulk InAs (upper). The lower portion shows the fit to the fittered data.

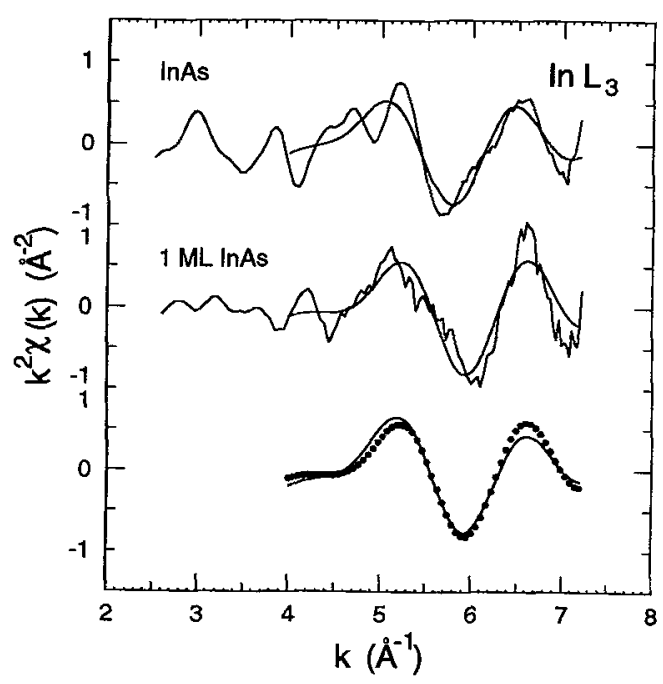

Figure 2: Photon-energy dependence of the reflectivity (lower) and the In-fluorescence yield (upper) near the GaAs(004) Bragg-backreflection condition. 
The elastic constants tabulated by Hornstra and Bartels ${ }^{1}$ render $\alpha=0.16$ for InAs, confirming the rigid-bond model. Note that equation 4 reproduces the conservation of volume $\varepsilon_{\perp}=-2 \varepsilon_{/ /}$when $\alpha \rightarrow 0$.

Because the strained layer is pseudomorphic with the GaAs substrate, $\Delta \mathbf{a} / /$ is known, and the distortions can be calculated. The compression in the first-neighbor bond length is $\Delta r=-0.053 \AA$, and the bond angles are shifted anisotropically with respect to the interface: $\Delta \theta=-7.5^{\circ}$ and $\Delta \theta^{\prime}=+3.8^{\circ} .11$ These distortions translate to an increase in perpendicular lattice constant $\Delta \mathrm{a}_{\perp}=0.44 \AA$, which is identical to the prediction of equation 1 .

To experimentally determine these distortions, we turn to our XSW and EXAFS data. Figure 2 shows the GaAs(004) reflectivity along with the best fit to the data points using the dynamical theory of $x$-ray diffraction. 12 Also shown is the In-XSW pattern compared to its best fit by the function

$$
\mathrm{Y}=1+\mathrm{R}+2 \sqrt{\mathrm{R} F} \cos (\phi-2 \pi \mathrm{D}) .
$$

The pertinent fitting parameters here are $D$, the interlayer-substrate distance in units of the reflecting-plane spacing $\left(\mathrm{d}_{\mathrm{GaAs}}(004)=1.4133 \AA\right)$, and $\mathrm{F}$, the coherent fraction of In atoms at $\mathrm{D}$. These values are determined to be $0.16 \pm 0.02$ and $0.72 \pm 0.1$, respectively, which locate the in atoms $1.64 \pm 0.03 \AA$ above the last As plane of the GaAs(001) substrate. 13

Table 1 compares our XSW measurement with $D$ as calculated from macroscopic-elastic theory (equation 1 ) and from equation 3 for bond-length $(\Delta r=0)$ and bond-angle $(\Delta \theta=0)$ conserving distortions. Also shown is the position of the layer had it not been strained, i.e., $D=a_{I n A s} / 4$. Because the experiment so closely coincides with the macroscopic prediction, the microscopic distortions must comply with the above formulae as well.

To test this hypothesis, figure 3 shows our In- $\mathrm{L}_{3}$ EXAFS from the InAs monolayer and from bulk InAs. Both are plotted with their Fourier-filtered first-shell contributions, which correspond to the In-As bond length. The raw EXAFS data clearly show that the first-neighbor bond in the strained-InAs layer is compressed relative to that in bulk InAs because the nodes of the spectrum are shifted towards higher-k values.

To obtain quantitative information, first-shell phase, $\phi(\mathbf{k})$, and amplitude, If(k)|, functions were extracted from the bulk InAs standard. The lower portion of the figure compares the Fourier-filtered first-shell EXAFS data from the InAs monolayer to its best fit by the function $\mathrm{k}^{2} \chi(\mathrm{k})$, where

$$
\chi(\mathrm{k})=\mathrm{N}|\mathrm{f}(\mathrm{k})| \sin [2 \mathrm{kr}+\phi(\mathrm{k})],
$$

using the phase and amplitude functions derived from the InAs standard. In the fit, the linear parameter N (the In-As coordination number) was calculated as the nonlinear parameter $r$ (the In-As bond length) was varied. The best fit was obtained with $\mathrm{N}=4.1$ and $\mathrm{r}=2.57 \pm 0.02 \AA .13$ Because the bulk In-As bond length is $2.62 \AA$, we find that the bond length in the strained layer is compressed $0.05 \pm 0.02 \AA$, in complete agreement with the theory developed above.

We should mention that the $\mathrm{Ge}_{\mathrm{x}} \mathrm{Si}_{1-\mathrm{x}} / \mathrm{Si}(001)$ work ${ }^{4}$ found no significant bond-length deviation from bulk alloys even though $\mathrm{x}$-ray diffraction measured a significant perpendicular lattice strain. However, in this case the strain was only $1 \%$, which, by the same model, gives an estimated bond-length compression of $0.01 \AA$. This small distortion is below the typical EXAFS detectability limit of $0.02 \AA$. The observable bond length compression here, $0.05 \AA$, is due to the much larger $7 \%$ strain inherent in the InAs/GaAs system.

In conclusion, we have determined the effect of strain on the bond lengths and lattice constants within an InAs monolayer grown epitaxially on GaAs(001). We feel our results are of general consequence to all strained-layer semiconductor systems.

1) J. Hornstra and W.J. Bartels, J. Cryst. Growth 44, 513 (1978).

2) M.G. Proietti, F. Martelli, S. Turchini, L. Alagna, M.R. Bruni, T. Prosperi, M.G. Simeone, and J. Garcia, J. Cryst. Growth 127, 592 (1993).

3) H. Oyanagi, Y. Takeda, T. Matsushita, T. Ishiguro, T. Yao, and A. Sasaki, Superlattices and Microstructures 4, 413 (1988).

4) J.C. Woicik, C.E. Bouldin, M.I. Bell, J.O. Cross, D.J. Tweet, B.D. Swanson, T.M. Zhang, L.B. Sorensen, C.A. King, J.L. Hoyt, P. Pianetta, and J.F. Gibbons, Phys. Rev. B 43, 2419 (1991).

5) M. Matsuura, J.M. Tonnerre, and G.S. Cargill III, Phys. Rev. B 44, 3842 (1991).

6) E. Canova, A.I. Goldman, S.C. Woronick, Y.H. Kao, and L.L. Chang, Phys. Rev. B 31, 8308 (1985).

7) M.G Proietti, S. Turchini, F. Martelli, J. Garcia, and T. Prosperi, J. Appl. Phys. 77, 62 (1995).

8) C. Lamberti, S. Bordiga, F. Boscherini, S. Pascarelli, G.M. Schiavini, C. Ferrari, L. Lazzarini, and G. Salviati, J. Appl. Phys. Lett. 64, 1430 (1994).

9) M.G. Proietti, S. Turchini, J. Garcia, G. Lamble, F. Martelli, and T. Prosperi, J. Appl. Phys. 78,6574 (1995).

10) N. Grandjean, J. Massies, and V.H Etgens, Phys. Rev. Lett. 69, 796 (1992).

11) To first order, $\Delta \theta^{\prime}=-1 / 2 \Delta \theta$.

12) B.W. Batterman and H. Cole, Rev. Mod. Phys. 36, 681 (1964).

13) Error bars indicate the spread of values which double the squared residual. 